\title{
Editorial: Updates to the DSE Leadership and Editorial Board
}

\author{
Timos Sellis ${ }^{1}$
}

Published online: 3 February 2022

(c) The Author(s) 2022

The Data Science and Engineering Journal (DSE) is starting its seventh year, continuing its successful journey since its inception in 2016. The journal continues to publish papers addressing fundamental challenges in data technologies and covering novel data-intensive applications. At the same time DSE also hosts issues with best papers selected from renowned international conferences. In 2021, we have also reached a major milestone: following the acceptance by SCOPUS, DSE has been selected for inclusion in the Emerging Sources Citation Index (ESCI), Web of Science with all its articles published since Volume 1, Issue 1 to be included in the database.

In our first editorial for 2022, I would like to announce an important change of DSE leadership, that of Professor Bin Cui joining DSE as Editor-in-Chief! Prof. Cui is not new in our DSE family, he has been serving in the role of associated managing editor since 2016, and of managing editor since 2018. His strong research track and leadership experience as well as his long association with the journal will be instrumental in taking DSE forward. I am thankful to Bin for his willingness to serve and look forward to working with him for the important task of DSE's development. With Bin on board, we are sure that the journal will continue to be a high-quality publication venue for relevant and exciting research. His bio follows.

At the same time, I would like to express on behalf of the whole journal team my sincere appreciation to X. Sean Wang, for his leadership of the journal for the past 4 years. He was the first EiC of the journal who took over from the very successful founding EiCs, Professor Elisa Bertino and Professor Jianzhong Li, and was instrumental to the establishment and development of the journal. Sean has been an amazing driving force behind DSE, always supporting quality and excellence in the journal and a great co-editor to work with! I do hope that Sean will continue to be involved with DSE, his experience and visionary thinking will always be useful to have.

This year will also see a significant change in our roster of Associate Editors (AEs). The founding AEs have completed their full terms (3 terms, 2 years/term) on 31 December 2021 and we will invite new AEs during the year to join us. We extend our sincere thanks and gratitude to all founding AEs: the success of this journal heavily relies on the efforts of the whole editorial team. We are grateful for their contribution to the growth of the journal and our collective efforts to make it a successful journal in the field of Data Science. We also thank for their willingness to stay on before we get all the new AEs on board in the interim period.

Starting January 2022, we welcome the following new Associate Editors as the first step of the plan:

- Yunjun Gao, Zhejiang University, China

- Xin Wang, Tianjin University, China

- Jianliang Xu, Hong Kong Baptist University, Hong Kong, China

All three are highly regarded scholars in the field of data science, and supportive to DSE as active journal authors and guest editors in the past years. We are very fortunate that these outstanding scholars are willing to volunteer their valuable time and indispensable expertise for handling manuscripts and promoting DSE for the benefit of our scientific community.

Finally, we welcome researchers to propose new special issue topics and submit their papers. And as always, we hope you will enjoy this issue and future issues of DSE.
Timos Sellis

tsellis@fb.com

1 Meta, Menlo Park, USA 


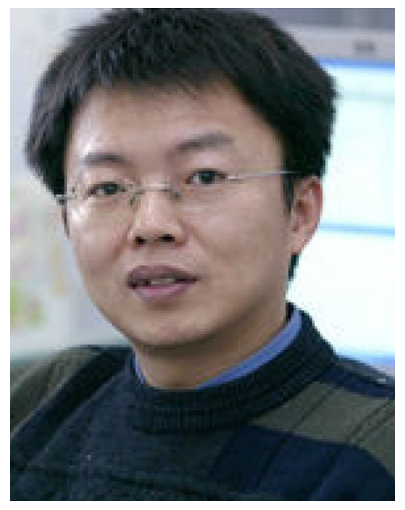

Bin Cui is a Professor in the School of Computer Science, Peking University, and has served as the Director of Institute of Network Computing and Information Systems since 2016. He obtained his B.Sc. from Xi'an Jiaotong University in 1996, and Ph.D. from National University of Singapore in 2004 respectively. His research interests include database system, big data management and analytics, and machine learning system.

$\mathrm{He}$ is currently serving in the Editorial Board of Distributed and Parallel Databases Journal and Information
Systems, and was a Trustee Board Member of VLDB Endowment (2015-2021), an Associate Editor of TKDE (2009-2013) and VLDB Journal (2011-2017). He was awarded Microsoft Young Professorship Award (2008), CCF Young Scientist Award (2009), Second Prize of Natural Science Award of Ministry of Education China (2014) and appointed as Cheung Kong Distinguished Professor by Ministry of Education China in 2016.

Open Access This article is licensed under a Creative Commons Attribution 4.0 International License, which permits use, sharing, adaptation, distribution and reproduction in any medium or format, as long as you give appropriate credit to the original author(s) and the source, provide a link to the Creative Commons licence, and indicate if changes were made. The images or other third party material in this article are included in the article's Creative Commons licence, unless indicated otherwise in a credit line to the material. If material is not included in the article's Creative Commons licence and your intended use is not permitted by statutory regulation or exceeds the permitted use, you will need to obtain permission directly from the copyright holder. To view a copy of this licence, visit http://creativecommons.org/licenses/by/4.0/. 